\title{
The potential of building integrated Photovoltaic (BIPV) systems for reducing the energetic impact of Italian supermarkets
}

\author{
Alessandro Franco ${ }^{*}$, Giacomo Cillari and Fabio Fantozzi \\ Department of Energy, Systems, Territory and Constructions Engineering, University of Pisa, Largo \\ Lucio Lazzarino, 56126 Pisa, Italy
}

\begin{abstract}
In the perspective of sustainable cities, urbanist and planners have to deal with a constantly increasing penetration of renewable energy systems (RES) in the urban structure: in tertiary sector, retail and supermarket stores as particularly energy-intensive compounds play a core role in this scenario, as they are often characterized by similar kinds of structures mostly, large surfaces and a single floor, and analogous composition of energy loads. Most of the current research focuses on energy efficiency, but these buildings are particularly interesting for a systematic application of PhotoVoltaic (PV) generation technology as the energy uses associated with them are mainly electrical, in connection with air conditioning and food cooling. This article analyses the energy consumption in the supermarket sector for the sale of food. After an analysis of the main energy consumption parameters, standard solutions for the sizing of PV systems are proposed based on different design objectives, highlighting the potential of each proposed solution. Results show that a high percentage of self-consumption can be achieved, and that a battery storage set at a mean daily PV potential production level $(4 \mathrm{kWh} / \mathrm{kW}$ in the case) perfectly suits to reach a self-sufficiency between $50-70 \%$. Retail and food stores have proven to be a perfect promoter for PV diffusion either in a high selfconsumption configuration, or turning them into energy hub for mobility to building or energy sharing policies.
\end{abstract}

\section{Introduction}

The civil and residential sector is responsible for about $40 \%$ of the total final energy consumption and for about $30 \%$ of greenhouse gas emissions [1]. The major possibilities of reducing the energy consumption lie in non-residential buildings, for public use, which are characterized by higher energy intensities (EI) if compared to residential ones [2].

In the European countries, at least $15 \%$ of the final energy is today used in the commercial service sectors; in particular food stores and supermarkets are considered quite "high energy intensive" due to their relevant need for thermal comfort, refrigeration and lighting systems, with a relevant amount of electricity use. Wu et al. presented a method to evaluate building

\footnotetext{
* Corresponding author: alessandro.franco@ing.unipi.it
} 
energy consumption based on energy use index of different functional sectors in China. The study testifies that the average value of supermarkets energy consumption is the highest one with respect to all the other tertiary sectors, [3].

In this specific field, energy efficiency measures are increasingly recognized as methods not only to achieve a sustainable energy supply and reduce greenhouse gas emissions with beneficial effect on the community, but also methods to reduce energy bills and increase brand value and recognition by means of corporate social responsibility strategies to improve customers' awareness about the implementation of energy efficient and eco-friendly technologies. Energy efficiency is, therefore, considered a strategic priority, [4].

Recent data on energy consumption in the supermarkets' sector, with reference to some specific structures and specific climatic conditions, show that the energy intensity, even if still quite high, has been largely reduced in the last ten years, mainly in the quite large structures (with floor surface higher than $700 \mathrm{~m}^{2}$ ), mainly in combination with the installation of energy-efficient technologies for all sub-systems, including refrigeration systems, HVAC for thermal control and lighting systems, [5-7]. Energy consumption of the supermarkets appears to be well correlated with both sales floor and total floor area: uncertainties exist on the average energy use intensity of supermarkets related to the different methodologies of calculation. For example, Tassou et al. showed electrical energy over sales floor area of between 770 and $1480 \mathrm{kWh} . \mathrm{m}-2$.year-1 from hypermarket to convenience size stores, [2]. Van der Sluis et al. showed specific energy consumption (SEC) values (total energy over gross floor area) of between 407 to $800 \mathrm{kWh} . \mathrm{m}-2$.year-1, from a Dutch supermarket chain and to Canadian stores, [8].

The consumption of a supermarket is distributed among the different areas identified in the supermarket associated with lighting, air conditioning, ventilation and cooling systems. A statistical analysis of the consumption of electricity permits to obtain average values. According to Mylona et al. [9] in supermarkets with high food goods ratio, refrigeration could be as high as 60\%: generally, the smaller the store the highest the energy use due to the higher refrigeration equipment used because of the higher ratio of food over non-food products. In the UK supermarkets, reported energy use by sub-systems assign $30-35 \%$ refrigeration, 20 $25 \%$ to HVAC and $15-20 \%$ to lighting $[10,11]$. The total energy use of a supermarket depends on business practices, store format, product to food ratio, equipment use for in store preservation and displays.

At the same time, the promotion of active measures for energy production using renewable energy systems (RES) is interesting too, because the relevant amount of electricity required makes possible to pursue the objective of net Zero Energy Building (nZEB) configuration and to pursue strategic programmes of rational use of the available sustainable resources, $[12,13]$. In particular, the structures for the sale of food are among the most interesting candidates for the installation of PhotoVoltaic (PV) modules aimed at selfproduction of energy, because the relevant use of energy in phase with the solar energy availability, make it possible to avoid the problem of placing the surplus of energy produced into the electrical grid.

In this perspective, the effective integration with the building of the variable, nonprogrammable RES, which will be the predominant energy source after 2030, appears to be really interesting in the perspective of a strategic diffusion of PV plants. Those are considered as vital contributors for the future energy transition strategy with its added advantage that can be sited everywhere and most importantly on buildings and developed areas where the actual load is, hence directly contributing to the optimal use of resources. The sector of food Supermarkets, due to the quite high energy load and the quite large availability of surfaces appears to be strategic in order to promote a further increase of Building Integrated PV (BIPV) plants. Given the high standardization of supermarket prefabricated structures, often similar in the different locations, linked both to construction efficiency and brand recognition, 
it is considered that indicators, derived from measured data in a bottom-up approach, can be useful, with appropriate scalability, for future design. Different strategies and configurations to maximize the energy self-consumption share, including proper system and storage sizing, demand-side management, and forecast, can be considered.

This paper after a general analysis and recognition of the main key performance indicators for quantification of energy use in food retail structures, try to define possible benchmark values according to the climate conditions and the kind of market structures, local or supermarket. The analysis ascertains and quantifies the annual energy consumption and cooling and heating demand of typical supermarket structures. Then the focus will be shifted on some specific case, represented by Italian supermarkets and after an analysis of the energy consumption parameters in the typical seasonal operating conditions and a comparison with the data obtained in similar structures located in different countries, try to define criteria and guidelines for the design of PV systems for producing energy for direct use.

Considering the abovementioned problems, the paper analyses the perspective of active methods for energy production, in particular PV plants, for reducing the carbon footprint of food retail structures and supermarkets. Starting from an extensive analysis of the energy consumption referred to two food retail structures, the paper proposes some possible sizing methodology for PV plants that have as objective the maximization of the share of selfconsumption of the energy produced.

\section{Supermarket sector and energy use: relationship among energy consumption, energy intensity and size of store}

In general tertiary sectors has a relevant implication on energy consumption. The type of buildings and the operation inside are quite different if one thinks to the various categories: office, shopping and commercial, sports, educational buildings, medical treatment and others. Within the commercial sector, the entire sector of food supermarket is considered one with the highest rates of energy consumption per square meter, considering the whole commercial sectors, [5]. The supermarket building is in general a rectangular, one floor building consisting of six different zones: in general sales, production, dry storage, bakery, delivery area and offices. Each different zone is served by a specific service plant. In the literature different classification can be identified, but in general it is evidenced the difference in terms of sales floor area, as reported in Table 1, in which, basing on the classification proposed in [5] and rearranged by the authors of the present paper, four different typologies are identified.

Table 1. A possible classification of food retails structures.

\begin{tabular}{|c|c|}
\hline Store type & Sales floor area \\
\hline Hypermarkets & $>6000 \mathrm{~m}^{2}$ \\
\hline Superstores & $1500-6000 \mathrm{~m}^{2}$ \\
\hline Supermarkets & $400-1500 \mathrm{~m}^{2}$ \\
\hline Convenience store & $<400 \mathrm{~m}^{2}$ \\
\hline
\end{tabular}

Food stores and supermarkets are energy intensive buildings and present a unique space conditioning challenge because of the interaction between the HVAC system and the 
refrigerated display cabinets. HVAC system provides thermal comfort for customers and staff but enable the maintenance of the sales area at appropriate levels necessary for nonrefrigerated product. In particular, HVAC system can be considered an important consumer of energy after refrigeration depending on system design, geographical location and controls. HVAC systems, developed in various layouts, involve many components that can be arranged in several ways, obtaining different configurations [14]. In general, five different processes can be considered to achieve all the air-conditioning services, namely heating, cooling, humidifying, dehumidifying, and ventilation [15]. Fig. 1 provides a typical layout configuration for a HVAC system. The total energy use of a supermarket depends on business practices, store format and size, product food ratio, equipment use for in store preservation and display, management of HVAC and lighting systems installed. Small supermarkets or convenience store $\left(<400-500 \mathrm{~m}^{2}\right)$ usually located within urban areas have higher energy intensity than larger supermarkets because of the high ratio of food against non-food products. In this case some recent papers estimate [7] that about $50-60 \%$ of the energy consumption is referred to the operation of refrigeration, while only $30 \%$ is correlated with HVAC operation. About $15-20 \%$ of final energy consumption is correlated with the lighting systems and miscellaneous electricity loads. Other relevant differences can be reconnected to climatic elements. The smaller the store the highest the energy use due to the higher refrigeration equipment used because of the higher ratio of food and non-food products [16]. As the total sales area increases, the refrigeration energy use share in the total energy use reduces and the lighting becomes more significant.

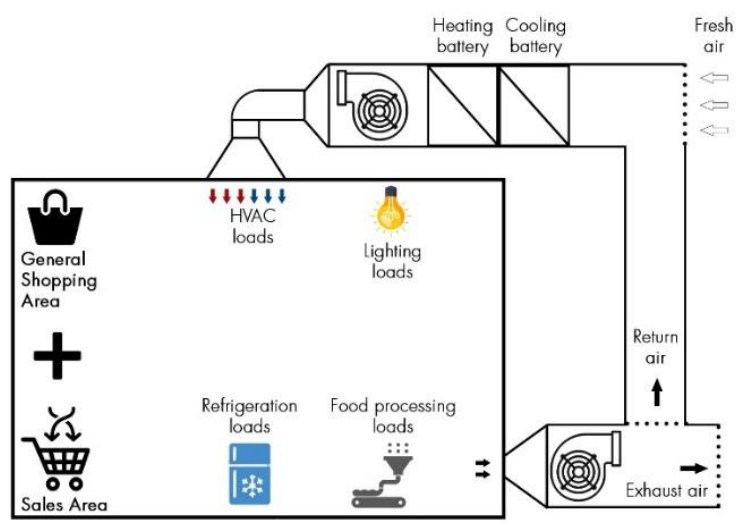

Fig. 1. HVAC system operation and supermarket common loads.

The EUI (Energy Use intensity) index or normalized EUI index is generally adopted to measure the overall energy use of building of public use [17]. The energy intensity of the supermarkets is in general a quite high value. Several studies in the literature states that the total energy consumption of shopping malls and supermarkets was the highest among the various tertiary activities. Wu et al. in [3] presented a method to evaluate building energy consumption based on energy use index of different functional sectors in China. Considering for example the food retail sector and supermarket analyzing a series of structures, the authors considers that EUI assumes values in the range between $150 \mathrm{kWh} / \mathrm{m}^{2}$. for each year and 450 $\mathrm{kWh} / \mathrm{m}^{2}$. A good correlation can be found among both sales and total floor area and supermarket energy consumption: the variable level of uncertainty is related to the average energy use intensity due to the different design of structures and, mainly, by the different reference for energy intensity computation. Data are partly based on total energy consumption, but sometimes they refer only to electrical consumption, ignoring the use of gas. Depending on the investigation, the EUI index is determined either on the total floor area 
or on the sales floor area. Anyway, even considering the incidence of these uncertainties, a wide range of variability still persists in the data. Ríos Fernández and Roqueñí in a recent paper, have correlated the energy intensity of the Spanish supermarkets to the floor area. The results are summarized in Table 2, [5].

Table 2. A possible classification of food retails.

\begin{tabular}{|c|c|}
\hline Exhibition and sale area $\left[\mathrm{m}^{2}\right]$ & Energy use intensity $\left[\mathrm{kWh} / \mathrm{m}^{2}\right.$ year $]$ \\
\hline $400-1000$ & 600 \\
\hline $1000-1500$ & 540 \\
\hline $1500-2000$ & 490 \\
\hline $2000-2500$ & 440 \\
\hline
\end{tabular}

Some authors from UK, considering the specific problem of energy consumption of food stores and supermarkets, show SEC values of stores structures widely differs from country to country even when the difference in calculation of energy intensity is taken into account: for example the electrical energy intensity in UK supermarkets appears to be 2.5 times as high as the value in Dutch supermarkets, [8]. As refrigeration is responsible for a large part of the energy used by stores, refrigeration capacity (RC) was considered to assess whether it correlated well with energy intensity, [18-19].

The problem of reduction of energy consumption of commercial structures has been recently considered in the scientific and technical literature. Some works have demonstrated how the introduction of efficiency measures, as enhanced utilization of daylight, a combination of natural and mechanical ventilation, improved refrigeration cabinets, with doors on frozen food cabinets, improved control over lighting and ventilation, and acceptance of a wider range of internal temperatures, LED display lighting [20] can have a wide impact on the final energy use in such structures. The various measures can be important in order to determine a reduction of the energy intensity (EI), [12, 13]. The use of such efficiency measures appears to be particularly relevant in smaller stores, in which refrigerated food typically takes up a greater proportion of floor area than it does in larger stores as larger stores will merchandise more non-grocery products. In general, even if the differences in the data are significant, we can certainly say that commercial structures such as supermarkets and superstores are highly energy-intensive. For those structures it becomes particularly interesting both the implementation of saving measures but mainly active measures with the relevant introduction of energy production from renewable sources.

\section{Supermarkets: typical energy consumption profile and role of energy efficiency measure and active production}

In the previous section we have analysed general consumption data of commercial structures for food sales by referring to average annual data and to the values of the average energy intensity. However, in order to design a PV plant for energy production, it is also useful to evaluate the variations in energy consumption over time. Several different parameters and variable can be used in order to determine the effective energy consumption: 
the calendar day, the number of opening hours, the customer's presence, external temperatures, humidity and daylight. With this objective, the consumption of two real structures, both located in the territory of Tuscany, in Italy, were monitored and examined. Figure 2 shows the hourly trend of energy consumption for one of the two case studied analysed. The data have been acquired on site through a monitoring activity. The rough data highlight the overall range of variation but is not useful to understand the actual behaviour of the supermarket and identify reference values for system sizing. The specific data of the two structures are provided in Table 3. It is observed that in this case there is a significant variation both within the single day and in the seasons. Since energy consumption is largely due to refrigeration, energy uses are more relevant during the summer season.

Table 3. Main energy data about the analysed supermarkets

\begin{tabular}{ccccc}
\hline $\begin{array}{c}\text { Case } \\
\text { Study }\end{array}$ & Kind of structure & $\begin{array}{c}\text { Total gross area } \\
{\left[\mathrm{m}^{2}\right]}\end{array}$ & EUI $\left[\mathrm{kWh} / \mathrm{m}^{2}\right]$ & $\begin{array}{c}\text { Peak demand } \\
{[\mathrm{kWh}]}\end{array}$ \\
\hline A & Supermarket & 16.000 & 0.51 & 803 \\
B & Local grocery store & 4830 & 0.27 & 106 \\
\hline
\end{tabular}

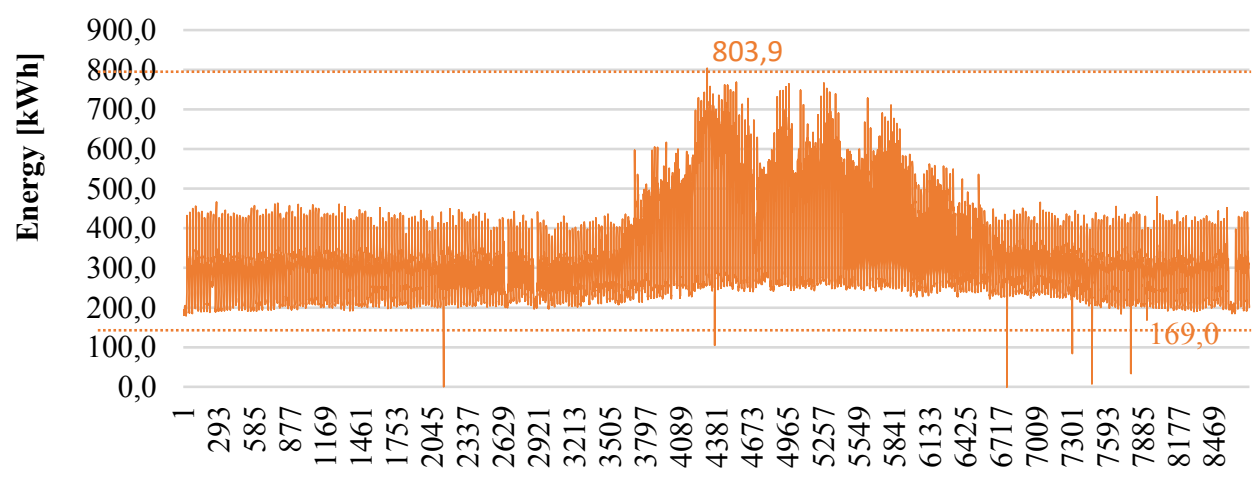

Time [hour]

Fig. 2. Hourly trend of energy consumption for the higher size supermarket (Case A)

To compare the structures under investigation with the benchmarks defined in the previous section, in Fig. 3 the hourly and average values of the energy intensity for both cases are reported. Figs. 4 and 5 instead, provide a clustering of the hourly range of energy demand.

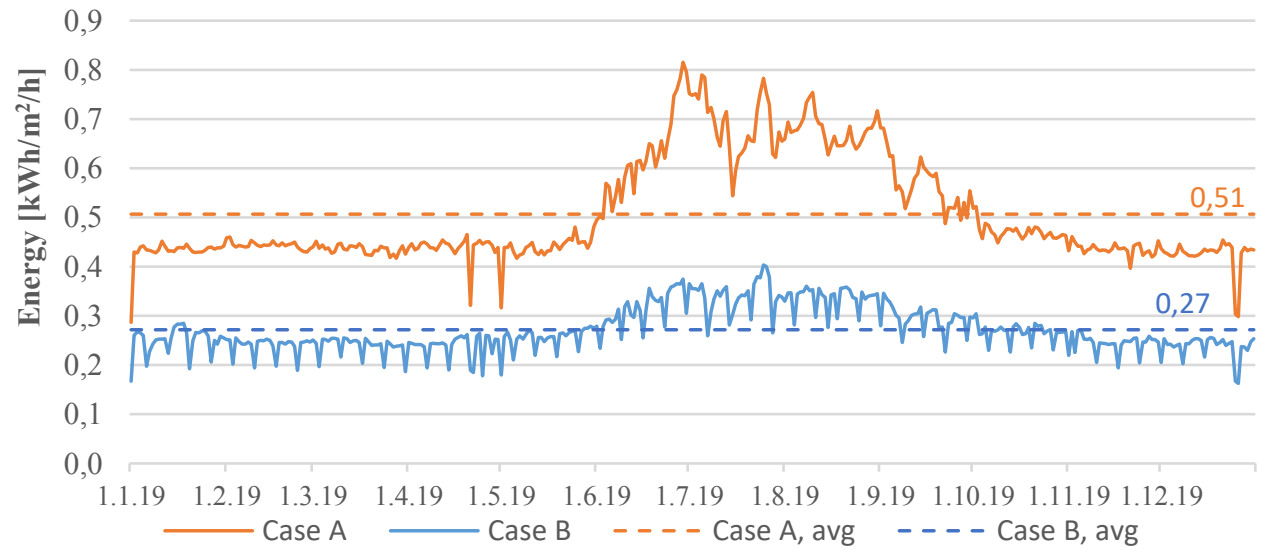

Fig. 3. Energy consumption profile for the two supermarkets under analysis. 
In particular in Figure 4 relative to Case A, provides the number of hours during the year in which a particular daily energy consumption is observed. It can be evidenced how a daily energy consumption in the range between 281 and $322 \mathrm{kWh}$ is observed for about 1900 hours. Similar data can be evidenced for structure of Case B too.

Some useful data can be extracted from the daily trend, the base load and both value and time location of the peaks of electrical demand: this data result to be fundamental for the accurate design of electrical RES. Reference data of energy consumption collected and monitored from the two structures are reported in Table 4.

In both Case A and Case B a base load can be evidenced: in particular, a mean hourly electrical demand of 190-200 kWh in the first case A and of 30-32 kWh in the latter one. The baseload is particularly correlated with the refrigeration loads and lighting systems that keep working when the structure is closed. The consistent and constant base load guarantees a reference value for the sizing of PV systems in a full self-consumption configuration. Looking at working days, the daily trend starts ranging between nigh time and day-time, with a slightly higher mean value of $264 \mathrm{kWh}$ and $47 \mathrm{kWh}$ for Case A and B respectively.

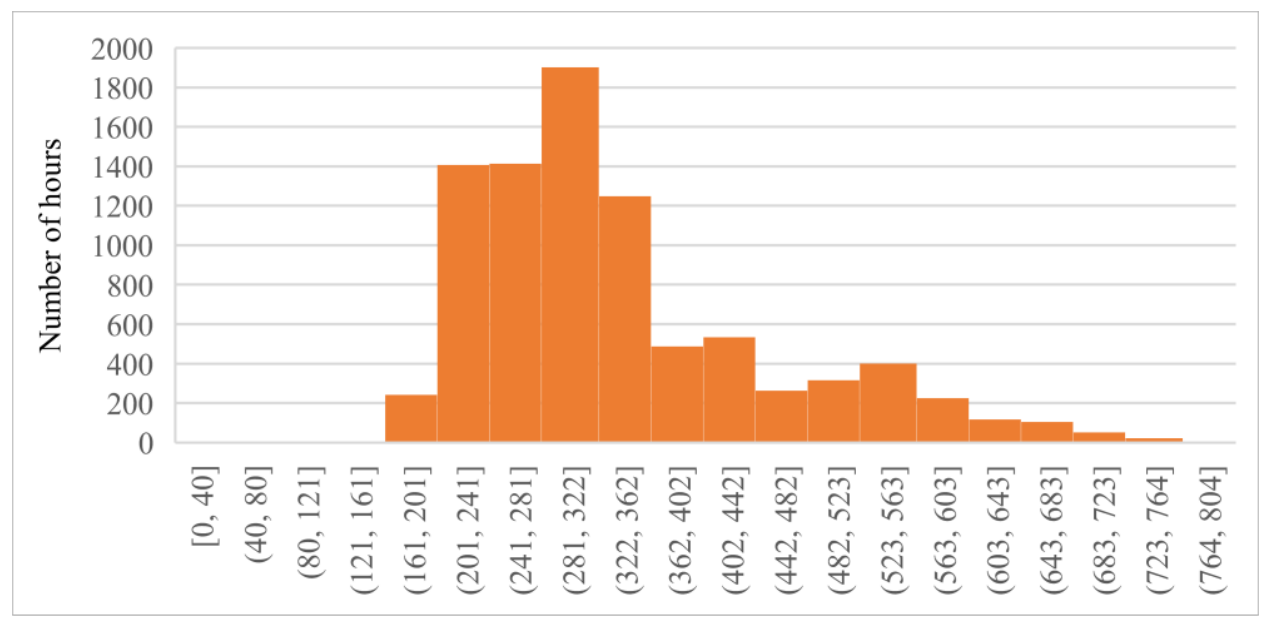

Fig. 4. Range of hourly energy consumption values for the first structure (A).

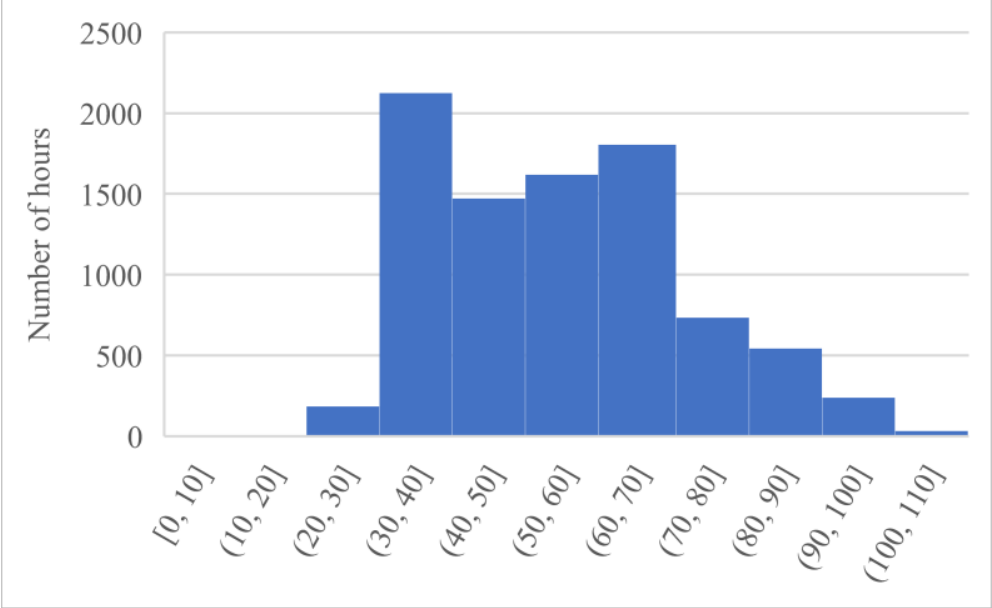

Fig. 5. Range of hourly energy consumption values for the second structure (B). 
Table 4. Reference indexes of energy consumption for Case A and B

\begin{tabular}{lcc}
\hline \multicolumn{1}{c}{ Parameters } & $\begin{array}{c}\text { Supermarket } \\
\text { (case A) }\end{array}$ & $\begin{array}{c}\text { Local Store } \\
\text { (Case B) }\end{array}$ \\
\hline Gross annual consumption [MWh] & 2959 & 479 \\
Annual average hourly consumption [kWh] & 337 & 54 \\
Maximum daily consumption [kWh] & 13045 & 1949 \\
Minimum daily consumption [kWh] & 4590 & 785 \\
Holydays average hourly base load [kWh] & 191 & 32 \\
Weekdays average hourly base load [kWh] & 264 & 47 \\
Annual hourly peak consumption [kWh] & 803 & 106 \\
Annual hourly base load [kWh] & 169 & 27 \\
\hline
\end{tabular}

\section{A strategic vision: the n-ZEB Supermarket using PV plants for energy production}

Measures to reduce the energetic impact of commercial structures as supermarkets and superstores fall into one of the following two categories: reducing energy consumption and embodied energy in buildings, switching to low-carbon fuels including a higher share of renewable energy, as PV power plants. PV plants are vital contributors in the future energy transition to a de-carbonized energy system due to the growing role of electricity, both in the supply of alternative fuels and in the final uses. The added advantage of PV lies in its installation flexibility as it can be sited everywhere and, most importantly, on the buildings and developed areas where the actual load is, hence directly contributing to the optimal use of resources. Energy system integration will grow in importance requiring the services of technologies, such as storage, as key enablers, both at a central and distributed level for flexible consumers. Flexibility at all levels has an increasing relevance: transforming the demand into a provider for optimal use of resources by turning the end users into prime providers of flexibility is a possible answer.

More than $600 \mathrm{GW}$ of solar PV power plants have already been installed worldwide, making solar PV the second renewable electricity source. A substantial portion of the PV installations until now are related to the randomness of feed-in tariffs established by local governments. The spread of Building-integrated PV (BiPV) can represent a new stable driving force for the diffusion of PV systems. The trend suggests a capillary widespread of RES mainly through small to medium PV plants right in the civil/residential sector. The supermarkets represent a strategic sector in this perspective. In this case, as observed in the previous section, direct use of the energy generated is an obvious choice, hence avoiding costly conversions. BiPV consists of PV modules that function as part of the building envelope (curtain walls, roof panels or shingles, shading devices, skylights). BiPV systems are sometimes installed in new 'showcase' buildings even before the systems are generally cost-effective.

Considering the two cases analysed in Section 3, the profitability and size of the PV power systems can be studied with various different objectives. On the basis of this parameters, deduced through the analysis and clustering of electrical consumption trend, different sizing strategies have been developed, according to different goals. The size of the PV plant can be defined with reference to different methods. From this values, three strategies, a full selfconsumption, a mean production level and an optimum with storage integration can be defined. In all cases an overall PV system efficiency of $85 \%$ has been considered. To address a full self-consumption, the holydays average hourly base load, the annual hourly base load 
or the minimum daily consumption can be used: in the latter, considering a solar summer irradiation condition $\left(7.95 \mathrm{kWh} / \mathrm{m}^{2}\right)$ in order to guarantee self-consumption, a maximum value of the peak power installed, $558 \mathrm{~kW}(\mathrm{~A})$ and $99 \mathrm{~kW}(\mathrm{~B})$, is achieved.

Looking at mean production levels on a year basis, the weekdays average hourly base load or the annual average hourly consumption can be considered as reference levels for mean consumption during the year: in the first case, this time compared to the local average solar irradiation $\left(4.06 \mathrm{kWh} / \mathrm{m}^{2}\right)$, a $1646 \mathrm{~kW}$ (A) and a $278 \mathrm{~kW}$ (B) PV plant is needed. The gross annual consumption represents another useful benchmark: an average sizing can be based on a share around $70 \%$ of the total annual energy demand, leading to a PV peak power installed for case A and B of $1474 \mathrm{~kW}$ and $226 \mathrm{~kW}$ respectively. In both cases the self-consumption (SC) share of the energy directly used decreases of about $20-30 \%$, but the self-sufficiency (SS) index, based on the share of energy demand covered by on-site production, highly increases, almost doubled. Table 5 shows the benchmarks used for the system sizing, along with energy produced with the PV plant $\left(\mathrm{E}_{\mathrm{PV}}\right)$ and flows from $\left(\mathrm{E}_{\mathrm{IMP}}\right)$ and to the grid $\left(\mathrm{E}_{\mathrm{EXP}}\right)$. To further optimize the sizing process, it must be based on the hourly trend of supermarket energy demand. To get most relevant effects by the use of on-site RES, the integration of a storage is needed, that add flexibility to the system and help offset the time gap between production and consumption. Table 6 summarizes the values achieved in terms of both PV and storage size, including the total energy stored $\left(\mathrm{E}_{\mathrm{ST}}\right)$. The storage is set at a mean daily $\mathrm{PV}$ potential production level, $4 \mathrm{kWh} / \mathrm{kW}$. In this case the optimization is based on the overall hourly trend of the consumption data monitored: even if ignoring the possible peaks of demand due to a wide, hourly, time step, being the load profile in a day smooth, the lost in accuracy is quite low.

Table 5. PV production data for different self-consumption levels with hourly data analysis

\begin{tabular}{ccccccccc} 
& \multicolumn{2}{c}{ Sizing benchmarks } & \multicolumn{3}{c}{ Energy flows } & \multicolumn{2}{c}{ Indexes } \\
\cline { 2 - 10 } Case & $\begin{array}{c}\text { Daily } \\
\text { demand } \\
{[\mathrm{kWh}]}\end{array}$ & $\begin{array}{c}\text { PV potential for } \\
\text { sizing } \\
{[\mathrm{kWh} / \mathrm{kW}]}\end{array}$ & $\begin{array}{c}\text { PV } \\
\text { size } \\
{[\mathrm{kW}]}\end{array}$ & $\begin{array}{c}\text { EPV } \\
{[\mathrm{kWh}]}\end{array}$ & $\begin{array}{c}\text { E EXP } \\
{[\mathrm{kWh}]}\end{array}$ & $\begin{array}{c}\text { EIMP } \\
{[\mathrm{kWh}]}\end{array}$ & $\begin{array}{c}\text { SC } \\
{[\%]}\end{array}$ & $\begin{array}{c}\text { SF } \\
{[\%]}\end{array}$ \\
\hline \multirow{4}{*}{$\mathrm{A}$} & 4590 & 6.98 & 558 & 626814 & 8965 & 2341322 & 99 & 21 \\
& 6336 & 3.27 & 1646 & 1848990 & 655519 & 1765700 & 65 & 40 \\
& 5675 & 3.27 & 1474 & 1655778 & 508570 & 1811962 & 69 & 39 \\
\hline \multirow{3}{*}{ B } & 785 & 6.76 & 99 & 117249 & 2003 & 363754 & 98 & 24 \\
& 1128 & 3.45 & 278 & 329247 & 126090 & 275843 & 62 & 42 \\
& 919 & 3.45 & 226 & 267661 & 77561 & 288900 & 71 & 40 \\
\hline
\end{tabular}

Table 6. PV production data for full self-consumption based on hourly data analysis

\begin{tabular}{ccccccccc} 
& \multicolumn{2}{c}{ System size } & \multicolumn{3}{c}{ Energy flows } & \multicolumn{2}{c}{ Indexes } \\
\cline { 2 - 9 } Case & $\begin{array}{c}\text { PV size } \\
{[\mathrm{kW}]}\end{array}$ & $\begin{array}{c}\text { Storage } \\
\text { capacity }[\mathrm{kWh}]\end{array}$ & $\begin{array}{c}\text { EPV } \\
{[\mathrm{kWh}]}\end{array}$ & $\begin{array}{c}\text { EST } \\
{[\mathrm{kWh}]}\end{array}$ & $\begin{array}{c}\text { EEXP } \\
{[\mathrm{kWh}]}\end{array}$ & $\begin{array}{c}\text { EIMP } \\
{[\mathrm{kWh}]}\end{array}$ & $\begin{array}{c}\text { SC } \\
{[\%]}\end{array}$ & $\begin{array}{c}\text { SF } \\
{[\%]}\end{array}$ \\
\hline \multirow{3}{*}{$\mathrm{A}$} & 480 & - & 539195 & - & 2404 & 2422379 & 100 & 18 \\
& 1330 & 5320 & 1494020 & 384238 & 7152 & 1472302 & 100 & 50 \\
& 2100 & 8400 & 2358979 & 856019 & 215894 & 816085 & 91 & 72 \\
\hline \multirow{2}{*}{ B } & 82 & - & 97116 & - & 482 & 382366 & 100 & 20 \\
& 220 & 880 & 260555 & 71218 & 1080 & 219526 & 100 & 54 \\
& 320 & 1280 & 378989 & 133211 & 34657 & 134668 & 91 & 72 \\
\hline
\end{tabular}


As it can be seen, starting from complete self-consumption without storage, in both cases the introduction of a battery system allows to increase the PV size by 2.7 times. Even an optimal size, based on a global balance between the two indexes, returns identical values, $91 \%$ of SC and $72 \%$ of SS. This again highlight how the standardization of this kind of structures and their management is a useful point for a general discussion and approach for the integration of RES, with appropriate scaling based on climatic factors and building dimensions. The graph of Fig. 6 shows the daily energy trend of three different strategies, namely full self-consumption, mean production and optimized solution obtained coupling a PV plant with storage, for the supermarket described as Case B.

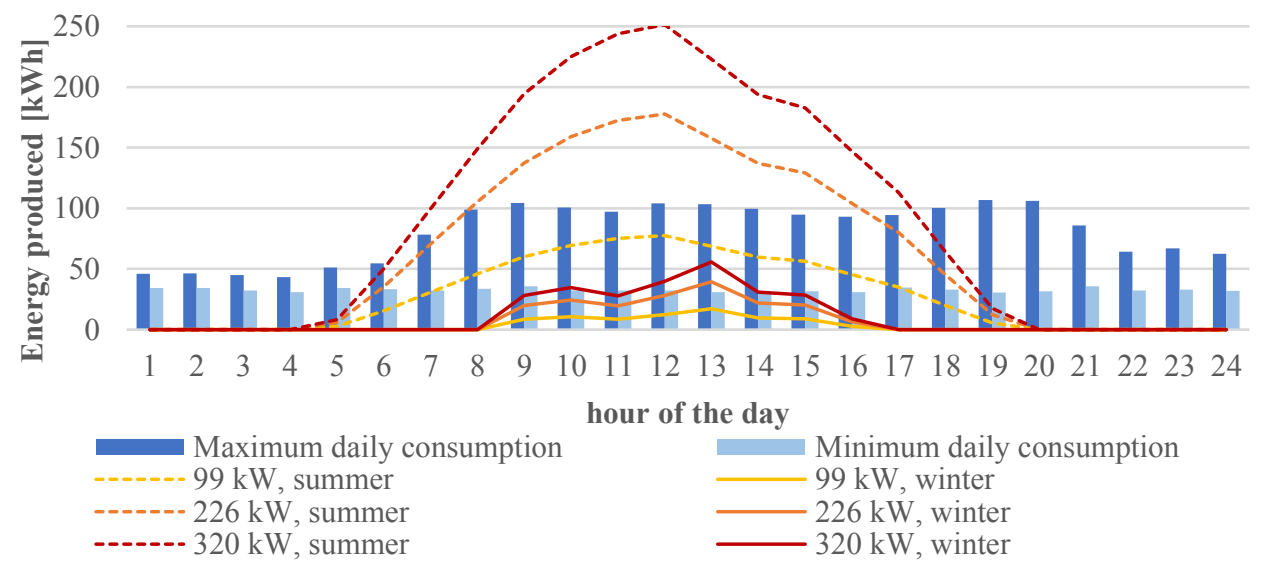

Fig. 6. Daily energy demand and energy consumption for three different strategies, case B.

The graph shows how hard is to match the load profile and the production trend as both varies along a day and between different season. Anyway, as it can be seen, the supermarket consumption profile, being quiet smooth and focused in daily hours, perfectly fit for PV integration: the PV plant of $99 \mathrm{~kW}$ peak power, shows a full self-consumption behaviour both in a summer and winter design day. The design day chosen corresponds to the maximum and minimum daily consumption days, that occur in the two different seasons of the year, respectively: this underlined the sensitivity of supermarkets to the building envelope performance according to the climatic conditions.

\section{Conclusions}

This paper provides work on the analysis of the energy performance of food retail stores and supermarkets basing on general analysis and on some real operational data. The design of PV plants to support the operation of energy systems for the food store, with different objectives is proposed. Two different cases are used for testing the methodology proposed, with different size and management, nominally a supermarket (A) and local grocery store (B). The analysis of the data monitored by the structure showed a EUI opposite to the trend highlighted by literature, with the smallest stores showing a lower value, $0.27 \mathrm{kWh} / \mathrm{m}^{2}$ than the supermarket, $0.51 \mathrm{kWh} / \mathrm{m}^{2}$ : this is mainly due to different schedule and opening times between the two stores. Anyway, no linear correlation occurs between EUI and size of the stores, but a common yearly trend has been evidenced, mostly influenced by the season of the year, being outdoor climatic conditions quite similar. The energy consumption, led by HVAC conditioning demand, decreases in winter and rise in summer, more than doubled during the day but with a low difference in night-time, as showed in Fig. 6. 
In general, it appears to be quite easy to define a PV plant that could be able to produce energy for the seasonal peak and covering an amount of the energy required for the whole year in the range between 40 and $60 \%$. The smooth trend of energy demand, with peaks in the middle part of the day, reflects how these kinds of building perfectly suits for a deep integration of RES electrical systems. A full self-consumption (98-99\%) can be reached by sizing the PV plant according to the minimum daily consumption and considering the summer solar irradiation condition. Moving to other reference for sizing, as the weekdays average hourly base or a share $(70 \%)$ of the total annual energy demand, including this time the local average solar irradiation, a reduction of $20 \%$ of the self-consumption occurs, but the self-sufficiency increases around $100 \%$. Both case studies showed quite similar indexes values, highlighting how these sizing strategies can be adapted to different size stores. It is surely more difficult to pursue the idea of defining the size of the plant according to a totally self-consumption strategy; in this case it is necessary a relevant oversizing of the plant and a relevant part of the energy produced need to be directed to the grid or wasted. Including an electrical storage set at a mean daily PV potential production level, a full self-consumption is achievable, but the PV power installed reaches high levels (2100-320 kW).

The data acquired through the analysis of the two store structures and the simulation carried out on possible PV sizing and integration evidenced the suitability of these sector to become a promoter for a wider diffusion of PV plant. Supermarket could easily host systems in a full self-consumption configuration, but they could also become, in the perspective of sustainable cities, energy hubs for energy sharing or mobility to building initiatives.

\section{References}

1. International Energy Agency, World Energy Outlook 2019, 2019. [Online]. Available on the website at: https://www.iea.org/topics/world-energy-outlook.

2. S.A. Tassou, Y.T. Ge, A. Hadawey, D. Marriott. Energy consumption and conservation in food retailing. Applied Thermal Engineering 31: 147-156 (2011).

3. J. Wu, Z. Lian, Z. Zheng, H. Zhang, A method to evaluate building energy consumption based on energy use index of different functional sectors, Sustainable Cities and Society, 53: 101893 (2020).

4. J.C. Rios-Fernandez, Economic and environmental improvements using high energy efficiency HVAC in supermarkets, Clean Technologies and Environmental Policy 22: 1417-1429 (2020). https://doi.org/10.1007/s10098-020-01881-4.

5. J.C. Rios-Fernandez, N. Roqueñí, Analysis of the potential of Spanish supermarkets to contribute to the mitigation of climate change. Sustainable Product Consum 14:122-128, (2018).

6. A. Hasan, A. Bahadori-Jahromi, A. Mylona, M. Ferri, H. Tahayori, Investigating the Potential Impact of Future Climate Change on UK Supermarket Building Performance. Sustainability 13: 33 (2021).- https://dx.doi.org/10.3390/su13010033.

7. Z. Mylona, M. Kolokotroni, A. S. Tassou, Coupling night ventilative and active cooling to reduce energy use in supermarkets with high refrigeration loads, Energy and Buildings 171: 26-39 (2018).

8. S. van der Sluis, U. Lindberg, A.L. Lane, J. Arias, Performance Indicators or Energy Efficient Supermarket Buildings. Proceedings of ICR 2015, Yokohama, Japan, 2015.

9. Z. Mylona, M. Kolokotroni, S. Tassou, Frozen food retail: measuring and modelling energy use and space environmental systems in an operational super- market, Energy Build. 144: 129-143, (2017). 
10. DECC, Non-domestic building energy use project phase I-pilot study of the food and mixed retails sector, 2013. [Online]. Available on the website at: https: //www.gov.uk/government/uploads/system/uploads/attachment_data/file/ 07319/DECC Non _ - _ domestic _ building _ energy _ use _ project _ phase _ I.pdf.

11. $\overline{\mathrm{S}}$. Tassou, Y. Ge, Reduction of refrigeration energy consumption and environ- mental impacts in food retailing, in: Handbook of Water and Energy Management in Food Processing, Woodhead Publishing, Cambridge, UK, 2008, pp. 585-611 .

12. A. Ferreira, M. Duarte Pinheiro, J. de Brito, R. Mateus, Combined carbon and energy intensity benchmarks for sustainable retail stores, Energy 165: 877-889 (2018).

13. S.Acha, Y. Du, N. Shah, Enhancing energy efficiency in supermarket refrigeration systems through a robust energy performance indicator. International Journal of Refrigeration 64: 40-50 (2016).

14. J. Cho, Y. Kim, J. Koo, W. Park, Energy-cost analysis of HVAC system for office buildings: Development of a multiple prediction methodology for HVAC system cost estimation, Energy and Buildings, 178: 562-576, (2018), ISSN 0378-7788, https://doi.org/10.1016/j.enbuild.2018.05.019.

15. R. McDowall, Introduction to HVAC, Chapter 1: in Editor(s): Robert McDowall, Fundamentals of HVAC Systems, Elsevier, 2007, Pages 1-10, ISBN 9780123739988, https://doi.org/10.1016/B978-012373998-8/50016-9.

16. J.L. Galvez-Martos, D. Styles, H. Schoenberger, Identified best environmental management practices to improve the energy performance of the retail trade sector in Europe. Energy Policy, 63: 982-94 (2013). https://doi.org/10.1016/j.enpol.2013.08.061.

17. Z. Mylona, M. Kolokotroni, S. A Tassou, A study of improving energy efficiency of small supermarkets by modelling interaction between building, HVAC, refrigeration and display product, Proc. of the 5th IIR Conference on Sustainability and the Cold Chain, Beijing China, 5-8 April 2018.

18. (EPA) USEPA. Energy Use in Supermarkets. [Online]. Available on the website at: https://www.energystar.gov/sites/default/files/tools/DataTrends_Supermarket_2015012 9.pdf

19. A. Foster, J. Evans, G. Maidment, Benchmarking of supermarket energy consumption. Proceedings of the 5th IIR Conference on Sustainability and the Cold Chain, Beijing, China, 2018.

20. A. Foster, T. Brown, J. Evans, G. Maidament, Relationship between specific energy consumption and size of supermarket stores, The 25th IIR International Congress of Refrigera-tion, Montreal, Canada, 2019.

21. F. Hill, R. Edwards, G. Levermore, Influence of display cabinet cooling on performance of supermarket buildings. Build Serv Eng Res Technol 35: 170-181, (2014). 